\title{
AS VIAS DE INTEGRAÇÃO DA MOBILIZAÇÃO SOCIAL NO CAMPO POLÍTICO
}

\author{
Pierre Teisserenc*
}

\begin{abstract}
Neste artigo são analisadas duas situações de integração no campo político. As situações foram identificadas, por meio de pesquisa qualitativa, em Territórios Quilombolas e em Reservas Extrativistas Marinhas situados no Pará. Uma corresponde a instrumento jurídico constitucional para reparar injustiças históricas, mobilizador de identidade específica em ação para interferir no poder local no município de Salvaterra (Ilha do Marajó). O caráter identitário dos pleitos e a inexistência de espaços públicos para negociá-los, reduz a possibilidade de alcance de direitos sociais. A segunda forma, a Resex - instrumento de política pública relacionado à mobilização mais social do que identitária - referida no reconhecimento das populações tradicionais e seus saberes-fazeres adequados às exigências ambientais. Ferramentas, como o Conselho Deliberativo, em determinadas circunstâncias, constituem espaços favoráveis a inovações no modo de vida, na produção econômica, no engajamento dos atores locais na ação coletiva, renovando-se assim a democracia local em um contexto de ambientalização.
\end{abstract}

PALAVRas-Chaves: Campo político. Mobilização social. Identidade. Poder local. Ambientalização

\section{INTRODUÇÃO}

O objetivo deste artigo é evidenciar a integração no campo político da mobilização social de comunidades em dois contextos sociais e institucionais diferentes da Amazônia brasileira - o contexto das comunidades quilombolas, mobilizadas para o reconhecimento e para a defesa de seus novos direitos, e o contexto das populações tradicionais, mobilizadas para satisfazer suas reivindicações territoriais no contexto de uma Reserva Extrativista (Resex). Este artigo se apoia nos resultados de pesquisas conduzidas em quinze comunidades quilombolas do município de Salvaterra, na Ilha do Marajó, as quais procuram ser reconhecidas como comunidades quilombolas de pleno direito, de modo a obter os benefícios que a Constituição brasileira de 1988 lhes concede. Para essas comunidades, o desafio reside no reconhecimento tanto do território como espaço de ocupação e de produção quanto de sua cultura, nele enraizada. Trata-se do locus em que nasceram seus

${ }^{*}$ Universidade Paris 13.

99, avenue Jean-Baptisite Clément, 93430. Villetaneuse. pierre-teisserenc@wanadoo.fr ancestrais, reivindicado como o território de afirmação de sua identidade (Castro, 1997). ${ }^{1}$ $\mathrm{O}$ segundo campo de pesquisa diz respeito às populações tradicionais que vivem nos municípios de São João da Ponta e de Curuçá, no nordeste do Pará, em grande parte constituídas de extrativistas e pesquisadores. Organizadas em comunidades, essas populações se mobilizam para o desenvolvimento sustentável de seu território no contexto de duas Resex marinhas criadas em 2003. Nesses três campos de pesquisa, a mobilização das populações e das comunidades se traduz especificamente pela politização das questões locais, que são acompanhados por engajamentos políticos, cujas diferentes modalidades este artigo procura descrever.

O artigo de Maria José da Silva Aquino Teisserenc $(2016)^{2}$ refere-se aos resultados de pesquisas realizadas em conjunto em duas Resex. Nesse artigo a autora se volta mais especifica-

1 "Esses grupos experimentam um movimento que pretende recuperar a identidade anterior de seu grupo, via construção identitária através de processos políticos de afirmação sobre o território [...] A reivindicação maior é o reconhecimento e demarcação de suas terras." (Castro, 1997, p. 236-237).

2 Artigo publicado neste mesmo dossiê do Caderno CRH, Salvador, v. 29, n.77, p. 229-242, Maio/Ago. 2016. 
mente para os efeitos da politização das questões locais num contexto de desenvolvimento da ambientalização, ${ }^{3}$ a partir do trabalho do Conselho Deliberativo. Neste artigo, serão utilizados os resultados dessas pesquisas para evidenciar o trabalho político produzido nas duas Resex pelos representantes das comunidades locais e de seus parceiros. Aliás, em artigo publicado recentemente (Teisserenc, 2016), o esforço para mostrar especialmente de que maneira, no contexto de Salvaterra, a autodefinição de uma categoria social não homogênea dos membros das comunidades quilombolas está na origem de uma mobilização que não se limita a satisfazer as exigências legais requeridas para defender os seus novos direitos, mas também se enriquece de uma expressão identitária coletiva. Essa mobilização é fonte de novos conflitos, que se manifestam especificamente no campo político.

Meu objetivo é não apenas analisar os efeitos políticos dessa mobilização social a partir de uma comparação entre essas duas situações - a dos quilombolas e a das populações tradicionais numa Resex -, mas também explicar suas diferenças. Para realizar esses objetivos, escolhi privilegiar uma análise dessas situações em termos de ação pública, na medida em que, para satisfazer os desafios ปै que elas têm em comum (os quais podem se ○. resumir à reivindicação de um direito à terra e ao reconhecimento de um território), o dispositivo proposto pelas autoridades brasileiras of se diferencia pelas filosofias políticas que as inspiram, cujos objetivos não são similares, e pelas modalidades da sua implantação. Essa constatação justifica a hipótese segundo a qual a seriam as diferenças de concepção desses dois oิ dispositivos de ação pública que, em grande $\vec{\circ}$

¿ิ๋ 3 Nós entendemos ambientalização como "um processo histórico de construção de novos fenômenos [...] relacio-

$\stackrel{\pi}{\perp}$ nado à construção de uma nova questão social, uma nova

స్ questão pública.” (Lopes, 2006, p. 34-35). Esse processo se

- manifesta nas mudanças da natureza dos conflitos sociais

I da sua formulação e num início de institucionalização.

Ele é acompanhado de uma interiorização da ideia de meio ambiente por grupos sociais de diferentes características. Ele contribui para conferir legitimidade a certas categorias sociais, em razão de suas predisposições ecológicas, e para atender a suas reivindicações (Teisserenc, 2010). medida, permitiriam explicar a diferença dos efeitos políticos da mobilização social em cada caso. Vejamos esse aspecto mais de perto.

\section{UMA PROBLEMÁTICA DE INTEGRA- ÇÃO DOS DESAFIOS DA MOBILIZA- ÇÃo SOCIAL NO CAMPO POLÍTICO}

No caso dos quilombolas, a Constituição de 1988 propôs seu autorreconhecimento, a título individual, como descendentes dos negros, com vistas à negociação com os poderes públicos federais, no contexto comunitário, da atribuição de um território, cujo direito de uso é conferido a cada comunidade ${ }^{4}$ (Santilli, 2005, p. 137-139). Disso resultou um engajamento que, realizado em dois momentos - primeiramente individual e, em seguida, comunitário -, contribuiu para uma mobilização social (analisada no artigo evocado acima), cujo conjunto de efeitos, no plano local, nós avaliaremos levando em conta a ausência de implicação das autoridades locais na negociação implantada no contexto do dispositivo. ${ }^{5}$

No caso das populações tradicionais envolvidas na criação de uma Resex, o dispositivo proposto pela lei $\mathrm{SNUC}^{6}$ visa a oferecer a essas populações o reconhecimento tanto do seu território quanto de suas competências para geri-lo, respeitando as exigências ambientais a partir de um contrato (Aubertin; Pinton, 1997). ${ }^{7}$ É o reconhecimento dessas

${ }^{4} \mathrm{O}$ artigo 68 do Ato das Disposições Constitucionais Transitórias precisa que, no contexto dessa decisão, a terra de ocupação das comunidades quilombolas seja "reconhecida como propriedade definitiva" e que ela seja uma terra de "uso comum".

${ }^{5}$ Com efeito, no dispositivo proposto pela Constituição para responder à situação dos quilombolas, as autoridades locais, que são diretamente atingidas por todas as implicações concretas resultantes dessa regulação, não são, em nenhum momento, solicitadas.

${ }^{6}$ Sistema Nacional das Unidades de Conservação, apresentado e votado em 2000.

7 "Ao aceitarem os objetivos ambientais, as populações adquirem um reconhecimento jurídico e identitário, que é acompanhado de direitos fundiários e de restrições de uso para se conformarem a esses objetivos [...] Esse contrato social define espaço político, identidade ecológica e inserção no mercado." (Aubertin; Pinton, 1996, p. 233) 
duas dimensões que justifica a ocupação e a gestão desse território. Diferentemente do dispositivo proposto às comunidades quilombolas, a criação de uma Resex é acompanhada de instrumentos (como um Conselho Deliberativo), de diagnósticos participativos (um plano de gestão elaborado de maneira participativa para garantir a sua implantação) e, finalmente, de recursos específicos (como apoios técnicos, conselhos de toda natureza - oriundos de parceiros especializados -, ajudas financeiras, etc.) para facilitar seu sucesso.

O quadro de análise que serviu para a interpretação de nossas pesquisas se inspira especificamente nas reflexões de Alain Touraine que, para se interrogar sobre o que se deve entender por atividade política no contexto atual, parte, na sua última obra, da constatação de que há uma "ruptura entre mobilização social e ação política” (Touraine, 2013, p. 116). Distanciando-se de uma concepção institucional da política que reflete a existência de uma sociedade política, ele nos convida a privilegiar a análise das condições segundo as quais uma mobilização social é levada a "se organizar em ações políticas” (Touraine, 2013, p. 102). Entre essas condições, Alain Touraine concede uma grande importância aos atores - tanto à sua aptidão para formular direitos e para se dotarem dos melhores meios para fazer com que esses direitos sejam reconhecidos, quanto à sua "vontade de agir e à confiança em sua própria capacidade de ação coletiva e individual" (Touraine, 2013, p. 610-612).

Para pensar a ruptura entre a mobilização social e a ação política, o quadro teórico proposto por Alain Touraine precisa ser completado por uma reflexão sobre a politização, a fim de que se possa compreender como a ação coproduzida sobre um território pelos atores locais acaba por se impor como ação política. As reflexões gerais sobre a politização desenvolvidas por Jacques Lagroye nos parecem perfeitamente adequadas, podendo ser aplicadas à análise de contextos territoriais, como testemunha o artigo de Maria José Aquino, já citado.
Segundo Jacques Lagroye, o fato de uma ação ser considerada como ação política resulta de um acordo prático (Lagroye, 2003, p. 12) entre atores, visando a requalificar como atividades políticas todos os tipos de práticas sociais, de relações e de engajamentos. O autor explica que essa requalificação é possível sempre que, num dado contexto, são encontrados atores "inclinados a transgredir as regras tradicionais que codificam o funcionamento da ordem social". O nível local se presta perfeitamente a esse gênero de acordo entre atores locais, preocupados em se engajar no desenvolvimento de seus territórios. Em seguida, veremos que, diferentemente do dispositivo proposto aos quilombolas para responder à sua situação, a Resex oferece um quadro jurídico e institucional que pode facilitar essas disposições no âmbito local.

Enfim, nosso quadro teórico se alimenta da abundante produção científica sobre a mobilização das comunidades amazônicas. Destacaremos dois aspectos dessa produção. $\mathrm{O}$ primeiro concerne às mudanças que, há algum tempo (em muitos casos), essas mobilizações sofreram e continuam a sofrer, em razão de um contexto de grande mutação: "Ao contrário da cabanagem em 1835, essas populações são capazes de estabelecer contatos e alianças com os movimentos da sociedade civil, tanto em âmbito nacional quanto internacional, o que lhes tem permitido pelo menos oferecer ao debate suas propostas" (Gonçalves, 2001, p. 130). Essa capacidade de estabelecer relações e alianças adquire ainda mais importância quando a questão ambiental se impõe como uma dimensão essencial para o desenvolvimento do território, contribuindo, com isso, para criar condições "históricas" capazes de passar de uma situação de solidariedade mecânica ou comunitária - para retomar as expressões de Durkheim e de Tönnies - para uma situação de comunidade orgânica ou de sociedade. Como explica Alfredo Wagner Berno de Almeida: "Insistimos no 'progressivo' porquanto vivemos uma situação histórica em que se constata a emergência de identidades coletivas, combinadas com cons- 
ciência ambiental profunda. Estas identidades objetivadas em movimentos sociais levam à defesa e à preservação dos recursos naturais, convergindo para formas organizativas e para relações associativas e contratuais que procuram transcender os laços de solidariedade comunitária. Tem-se, portanto, uma situação histórica específica em que os movimentos sociais, num estratagema singular, articulam relações comunitárias com relações associativas.

[...] Nos termos de Bourdieu, privilegiando a percepção política, se poderia falar da transformação de uma existência atomizada em uma existência coletiva, com representações organizadas em movimentos sociais (Berno de Almeida et al., 2010, p. 334).

O segundo aspecto dessa produção científica diz respeito à atenção que ela concede aos objetivos dessas mobilizações, que visam, prioritariamente, a defender os novos direitos a que as populações beneficiárias podem aspirar, os quais, além de se materializarem no reconhecimento de um território, também permitem afirmar a diferença dos seus modos de vida e de produção e reivindicar seu reconhecimento no nível do território:

São movimentos de reexistência, posto que não só lutam para resistir contra os que matam e desmatam, mas por uma determinada forma de existência, por um determinado modo de vida e de produção e por modos diferenciados de sentir, agir e pensar" (Gonçalves, 2001, p. 130). ${ }^{8}$

Esses objetivos permitem compreender o caráter identitário dessas mobilizações. Disso resulta, para os quilombolas, o fato de que "sua identidade [remanescente de quilombo, de referência jurídica] emerge como resposta atual diante de uma situação de conflito e confronto com grupos sociais, econômicos e agências governamentais, que passam a implemen-

${ }^{8}$ Esses movimentos de resistência e de reexistência permitem, como afirma Enrique Leff, a essas populações "reinventar suas identidades em relação aos outros e à natureza. Não apenas revivem no panorama político como novos movimentos que reivindicam espaços em um mundo objetivado e economicizado. [...] Despertam seus sonhos, renascem suas utopias, para reinventar sua existência, para passar do ressentimento pela opressão ao ressentimento de sua vida" (Leff, 2006, p. 501). tar novas formas de controle político e administrativo sobre o território que ocupam e com os quais estão em franca oposição" (O’dwyer, 2002, p. 77). Para reforçar sua mobilização social e traduzi-la em engajamentos políticos, as populações tradicionais, por sua vez, tiram vantagem de uma diversificação e de um enriquecimento dos "repertórios de ação coletiva" (Tilly, 1986), ocasionados pela criação da Resex e pela integração das questões ambientais.

Nas páginas a seguir, propomo-nos a apresentar os dois dispositivos em seu contexto territorial e evidenciar os efeitos políticos da mobilização social que, em cada caso, eles produzem.

\section{DUAS CONCEPÇÕES DE AÇÃO PÚBLICA EM RESPOSTA A DUAS SITUAÇÕES EM DOIS CONTEXTOS TERRITORIAIS DIFERENTES}

\section{Apresentação dos dois tipos de comunida- de em seu contexto territorial}

No que diz respeito às quinze comunidades de Salvaterra, já foi constatado o caráter paradoxal de sua organização que, ao mesmo tempo em que consegue ser realizada de maneira relativamente consensual, para defender seus direitos e interesses (de acordo com as exigências da Constituição), dificulta cada vez mais aos membros dessas comunidades a organização de uma frente comum e o desenvolvimento de estratégias coletivas para se constituírem como sujeito político e para exercerem uma influência sobre o poder local. Disso resulta uma assimetria entre a capacidade de mobilização dessas comunidades para defender seus direitos e as dificuldades que elas encontram para pesar na cena política. Essa assimetria se explicaria precisamente pelo descompasso observado entre as exigências do dispositivo proposto pela Constituição Brasileira, que atribui ao Governo Federal todas as competências em matéria de tratamento da si- 
tuação dessas comunidades, ${ }^{9}$ por um lado, e a vontade dessas comunidades de pesar na cena política, a fim de defender a aplicação de seus novos direitos e de obter uma resposta favorável ao conjunto de suas reivindicações, por outro. Os conflitos resultantes desse descompasso estão na origem de uma politização das questões locais e das estratégias individuais e coletivas para exercer pressões no campo político local. Isso se manifestou, sobretudo, nas três últimas eleições locais, que corresponderam ao período em que as referidas comunidades se engajaram na negociação com as autoridades federais para regularizar sua situação, de acordo com a Constituição.

Para compreender o que estava politicamente em jogo nessa mobilização e seus limites, é importante lembrar que, até recentemente, essas comunidades tenderem a viver à margem, num contexto marcado pela perenização de um sistema de dominação. Esse sistema se exerce "até hoje pela elite rural tanto no Marajó como em outras regiões da Amazônia e seus efeitos sobre as comunidades são a quebra das relações de reciprocidade entre as famílias que compõem essas coletividades e a manutenção da sua dominação" (Gomes, 2005, p. 241). Ele se manifesta pela recorrência de conflitos locais pelo uso da terra. Para Flávio Gomes, é claro que a implantação do dispositivo de resolução da situação das comunidades quilombolas com o apoio do poder federal não muda muito essa situação e que "estas lutas e a resistência à escravidão, feitas de diversas formas, continuam ainda hoje, quando comunidades localizadas no município de Salvaterra, [que] se autodefinem como remanescentes quilombolas, são descendentes daqueles que, por gerações, lutaram de diversas maneiras para garantir seu direito à terra e à liberdade" (Gomes, 2005, p. 241).

${ }^{9}$ Lembremos que o dispositivo proposto aos quilombolas pela Constituição para responder à sua situação privilegia um tratamento comunitário dessa situação a partir da livre escolha de seus membros de se reconhecerem como quilombolas em virtude do princípio de autodefinição e que esse tratamento coloca em questão as relações contratuais que essas comunidades são convidadas a desenvolver com o INCRA como instituição pública do Governo Federal e, eventualmente, com esses parceiros.
No que diz respeito às populações tradicionais de São João da Ponta e de Curuçá, sua mobilização, que levou à criação da Reserva, ${ }^{10}$ beneficiou-se do trabalho realizado pela Igreja Católica, em particular da sua organização das famílias em comunidades e da formação de líderes com base na ideologia da Teologia da Libertação (Teisserenc, 2009, p. 58). Desde a criação da Resex, essa mobilização se beneficia do apoio de outros parceiros institucionais (os numerosos serviços técnicos, as universidades e os diversos tipos de especialistas convidados para resolver os problemas, à medida em que eles se colocam). Esse apoio se manifesta especificamente no interior do Conselho Deliberativo e nos seus efeitos, na melhora da qualidade de condições de vida das populações, no reconhecimento de seus conhecimentos tradicionais e na renovação de suas práticas de produção. Sem entrar aqui em detalhes sobre as transformações ocasionadas em cada um dos municípios pela criação da Resex ${ }^{11}$ (Teisserenc, 2009, 2014), chamaremos a atenção, em particular, para a mudança ocasionada pela eleição para prefeito em 2008, tanto na comunidade São João da Ponte, que elegeu o antigo presidente dos usuários da Reserva - um presidente que desempenhou um papel determinante na criação da Reserva -, quanto na comunidade de Curuçá, que elegeu o representante de uma das famílias de notáveis da região. Homem ambicioso e empreendedor, ele teve a inteligência de fazer uma aliança com os representantes da Reserva ao escolher como vice-prefeito um líder local que, considerado como um bom técnico e como um militante reconhecido no interior da Igreja católica, também desempenhou um papel determinante na criação da Reserva.

${ }^{10}$ É o Presidente da República quem decide sobre a criação de uma Resex; mas essa escolha, aparentemente, leva em consideração a situação das forças sociais de um território para evitar o fracasso de um dispositivo tão difícil de ser implantado.

${ }^{11}$ Dois dos meus artigos publicados anteriormente permitem que o leitor disponha de dados mais precisos sobre as transformações sofridas por essas duas reservas desde sua criação. 
O que os dois instrumentos de ação pública, a Resex e o dispositivo implantado para responder à injusta situação vivida pelos quilombolas, têm em comum

Essas duas situações - a das populações tradicionais no interior das Resex e a das comunidades quilombolas que se engajam para fazer valer os seus novos direitos - possuem um problema em comum claramente identificado, ao qual os poderes públicos decidiram dar uma resposta que, nos dois casos, foi justificada por imperativos morais, sociais e políticos. No que concerne às comunidades quilombolas, trata-se de reparar uma situação de injustiça histórica, a respeito da qual as diferentes constituições criadas pela República, desde a sua promulgação, contemporânea à abolição da Escravidão, jamais tinham se pronunciado.

No espírito da Constituição de 1988, o dispositivo proposto aos quilombolas resulta do trabalho de reparação de uma injustiça histórica para com essas comunidades (Santilli, 2005, p. 176). ${ }^{12}$ No que concerne às populações ditas tradicionais, majoritárias na Amazônia rural brasileira, uma das preocupações da Resex foi propor-lhes um estatuto, num contexto marcado pela implantação de uma política voluntarista engajada desde os anos If 60, sob a forma de uma nova colonização do : território amazônico, e criar as condições para seu reconhecimento como atores com plenos direitos sobre esses territórios "conquistados". Ao mesmo tempo, esses territórios se apresentam como territórios em desenvolvimento, que, geralmente, sofrem os efeitos devastadores dessa nova colonização, inspirada por uma \& globalização que ignora as questões levantadas oิ pela gestão da biodiversidade e da sociodiver-

12 Juliana Santilli apresenta nesses termos os argumentos para o reconhecimento dessas populações: "O reconhecimento de direitos territoriais especiais aos quilombolas

- busca reparar a opressão imposta aos negros e o regime

I escravocrata e, portanto, são também direitos 'históricos",

(Santilli, 2005, p. 177). Disso resulta o reconhecimento

de "direitos territoriais especiais assegurados pela Consti-

tuição" (Santilli, 2005, p. 137), pelo fato de os quilombolas

serem considerados como "minorias étnicas, culturalmente diferenciadas" (Santilli, 2005, p. 169). sidade. Nesse contexto, o reconhecimento proposto a essas populações consiste, como nós precisaremos, na participação numa gestão da biodiversidade de seu território, de modo a responder às exigências ambientais.

Assim, ambas as situações se beneficiaram de um tratamento específico resultante da implantação de um dispositivo de política pública que, apresentando-se, no caso dos quilombolas, sob a forma de um quadro regulamentar proposto pela Constituição, concede ampla espaço para a negociação entre os representantes do Estado e as comunidades, com a contribuição de especialistas em direito e em ciências sociais. ${ }^{13}$ No caso das populações tradicionais, o dispositivo proposto pela lei SNUC, a Resex, é um instrumento de política pública particularmente original e pertinente (Teisserenc, 2009), cuja criação é acompanhada da participação de parceiros científicos e técnicos, a fim de garantir seu bom funcionamento a partir do uso dos recursos que lhes são destinados e dos diferentes instrumentos mobilizados pela sua implantação, como o Conselho Deliberativo, os diagnósticos e os planos de gestão. Nos dois casos, a aplicação desses dispositivos resulta de uma abordagem experimental, na medida em que não há normas formais nem modelos de referência que se imponham aos tomadores de decisão, sejam eles nacionais ou locais.

Cada um desses dispositivos se justifica por uma vontade política de reparar uma situação de injustiça ligada à história, no caso dos quilombolas, e de uma situação de carência estatutária, no caso das populações tradicionais, num contexto geral - por causa da globalização - de fragilização de cada uma dessas situações. Esse contexto se manifesta particularmente pelas ameaças que pairam sobre seu território de ocupação, como a deflorestação ou o desenvolvimento da pesca industrial, sem contrapartida em matéria de gestão da biodi-

${ }^{13}$ Com efeito, o dispositivo proposto prevê a intervenção de antropólogos e historiadores para acompanhar o trabalho de identificação das comunidades e seu reconhecimento pelos poderes públicos. 
versidade desses territórios.

Nos dois casos, o reconhecimento dessas populações comporta três dimensões: um reconhecimento jurídico, que lhes confere um estatuto particular e lhes propõe um direito de uso da terra, segundo modalidades específicas de cada caso; um reconhecimento social e identitário, com referências às características e às qualidades dessas populações em relação a uma cultura, no caso dos quilombolas, e de um conhecimento tradicional, no caso das populações extrativistas. Esses dois tipos de reconhecimento se concretizam pelo reconhecimento de um território de pertencimento que é, ao mesmo tempo, um território de produção econômica e de afirmação identitária.

Por fim, observemos que a implantação desses dois dispositivos resulta de uma forma particular e paradoxal de descentralização, no sentido de que, em cada caso, é o Governo Federal que assume a iniciativa de trazer uma resposta à situação dessas populações e que garante sua continuidade, segundo modalidades diferentes em cada caso, enquanto que o conjunto de medidas de aplicação - seja o reconhecimento do território e a liberdade concedida a essas comunidades de se desenvolver da maneira mais autônoma ou mais específica - interpela a responsabilidade das autoridades locais, que geralmente estão pouco implicadas nos dispositivos propostos ou, até mesmo, simplesmente ausentes deles. Disso resultam diferentes tipos de conflitos, em cada caso, e um risco de desestabilização da sociedade local, como teremos oportunidade de mostrar em seguida.

\section{A mobilização social resultante em cada situação}

Nas duas situações, a politização das questões que estão em jogo localmente se impõe como um dos resultados da mobilização social, coetânea à implantação do dispositivo. Essa mobilização procede por meio de uma densificação das relações entre as comunida- des e seus membros, sob a forma "de uma dinâmica pública de justificação, de denúncia e de reivindicação”, materializada por meio de experiências comuns e de ações que podem ser explicadas em termos de "regimes de proximidade" (tendo em vista, sobretudo, os "laços de familiaridade com as coisas e com as pessoas"), bem como de "regimes de ação pública", na medida em que a produção dessas ações questiona os parceiros públicos (Mota, 2011, p. 255-256). Nos dois casos, a mobilização se manifesta como "um processo coletivo de autoconstituição que se faz em meio a lutas e conquistas, tanto para a afirmação de sua identidade como para terem acesso ao controle de seus territórios, ressaltando que esse processo passa pelo estabelecimento de regras de conservação, bem como pela formação de alianças com agentes externos” (Sant'ana; Pires Miranda, 2013, p. 111). Os referidos parceiros são aqueles que, há muito tempo, apoiam as populações - é esse o caso, em particular, de certas instituições da Igreja Católica -, aos quais se juntam, no contexto de implantação do dispositivo, novos parceiros (alguns dos quais são exteriores ao território) -, que são levados a desempenhar um papel essencial na consolidação do dispositivo. Para as comunidades quilombolas de Salvaterra, o principal parceiro é o movimento de defesa das populações “negras”, a Coordenação das Associações das Comunidades Remanescentes de Quilombos do Pará (Malungu), no interior do qual Luzia Betânia Alcântara, uma das principais líderes, assume importantes responsabilidades. ${ }^{14} \mathrm{E}$, para as populações tradicionais de Curuçá e de São João da Ponta, um dos principais parceiros é a CNPT, que abriga Sandra, uma das principais lideranças locais. ${ }^{15}$

${ }^{14}$ Com efeito, Bete, como é mais conhecida Luzia Betânia Alcântara, obteve uma formação jurídica, social e política de dois anos na CNBB da Igreja Católica de Belém, o que lhe permitiu assumir o papel de líder do movimento social "negro", antes de assumir as responsabilidades no interior da Malungu como conselheira da Presidência, como tesoureira e como coordenadora regional.

${ }^{15}$ Sandra foi, sucessivamente, Presidente da Associação dos Usuários da Resex Maré grande de Curuçá, antes de se tornar membro do Conselho de Administração do CPT 
Em cada um desses dois casos, o processo coletivo é, como afirma Alfredo Wagner Berno de Almeida, alimentado pela existência de um "potencial de mobilização" resultante das expectativas das comunidades quilombolas e das "raízes locais profundas e dos laços de solidariedade" (Berno de Almeida et al., 2008, p. 70) que a implantação do dispositivo permitiu reavivar. Esse processo coletivo está na origem de uma densificação das relações sociais, ${ }^{16}$ o que, sempre que as circunstâncias facilitam a emergência de uma dinâmica de integração desse processo coletivo no campo político, permite aos cidadãos "ultrapassarem suas divisões e formar alianças, constituir uma força consequente em termos de visibilidade e, talvez, ganhar um reconhecimento legal e político" (Cefaï et al., 2011, p. 49).

Nesse sentido, compreende-se por que é imperativo que identifiquemos as circunstâncias que permitem à mobilização encontrar um eco no campo político e descrever os efeitos dessa mobilização nesse mesmo campo. Mas, antes de proceder a essa análise, vejamos mais de perto qual é a diferença entre esses dos tipos de ação pública, a fim de poder avaliar os efeitos particulares desses dispositivos em matéria de mobilização social e de sua integração no campo político.

\section{O que diferencia esses dois tipos de ação política}

Segundo a hipótese que nós privilegiamos, a diferença entre essas duas situações se 2 explicaria pela filosofia política que inspira a cada um desses dispositivos, pelos objetivos

S e representante da Reserva de Curuçá no Conselho Deliberativo da Resex de São João da Ponta.

${ }^{16}$ Nosso artigo sobre a mobilização das comunidades quilombolas mostra de que maneira essa densificação das relações sociais é acompanhada pelo desenvolvimento de

- novas práticas, em particular das práticas de mutirão, que

Ti testemunham a importância da solidariedade nesse con-

texto e uma afirmação acentuada da identidade quilombola, que se manifesta no desenvolvimento de festas religiosas e laicas, de ritos e de uma vontade de integração da história quilombola e do aprendizado de práticas culturais quilombolas nas escolas. que eles buscam e pelas modalidades de sua implantação. No que concerne à situação dos quilombolas, a resposta dada pela Constituição de 1988 repousa sobre um duplo paradoxo. O primeiro (já evocado) resulta do fato de que, ao mesmo tempo em que cada um dos membros das comunidades é instado a se autodefinir pessoalmente como descendente de quilombolas, exige-se desses mesmos membros uma resposta coletiva por parte de cada uma das comunidades, às quais a propriedade da terra é concedida com vistas ao uso comum.

O segundo paradoxo é a consequência do fato de que a competência para gerir o processo de reconhecimento das comunidades quilombolas pertence às autoridades federais que, embora sejam diretamente atingidas pelas implicações concretas resultantes desse tratamento, em nenhum momento participam do dispositivo de reconhecimento. Isso instaura conflitos entre o nível federal e o local, por um lado, e o campo político, por outro, e entre o poder local e as comunidades quilombolas, preocupadas em reivindicar a aplicação de seus novos direitos no nível do território municipal, como demonstramos no artigo citado. Esses conflitos são atiçados pelo dilema representado para cada quilombola de se reconhecer como "negro" no contexto da sociedade brasileira (que aparece como uma sociedade discriminante), sem que se beneficie, como contrapartida, de qualquer vantagem, exceto a propriedade de uma terra de "uso comum" e sem que disponha de uma instância apropriada para fazer valer e defender os seus novos direitos.

As características do dispositivo proposto aos quilombolas pela Constituição permitem compreender por que, na ausência de qualquer instância no contexto local para defender seus direitos e interesses, sua mobilização de natureza identitária produz uma politização conflituosa das questões locais, tornando difícil a integração de suas reivindicações no campo político, como teremos oportunidade de verificar. O dispositivo oferecido pela criação da Resex às populações tradicionais com vistas a 
seu reconhecimento é bem diferente, na medida em que sua implantação é, como já salientamos, acompanhada de uma panóplia de recursos e instrumentos, como, por exemplo, o Conselho Deliberativo, cujo funcionamento e cujo trabalho convidam as autoridades locais e os numerosos parceiros para participar do desenvolvimento sustentável do território da reserva. Diferentemente das comunidades quilombolas, as populações tradicionais envolvidas na criação de uma Resex não se beneficiam de um direito de propriedade da terra - que é comunitária -, mas de um direito de uso da terra, no contexto de um contrato existente entre o Estado, que permanece sendo o proprietário da terra, e as populações, que se engajam em assumir sua gestão, respeitando as exigências ambientais com base nos "saberes nativos" reconhecidos pelo contrato (Aubertin; Pinton, 1997). ${ }^{17}$

$\mathrm{Na}$ origem desse reconhecimento das populações tradicionais através da criação da Reserva Extrativista, são levados em conta não apenas os fatores identitários, como é o caso dos quilombolas ${ }^{18}$ (Magalhães Lima, 2002, p. 17), mas, sobretudo, a necessidade de responder às questões sociais, a qual se traduz pelo reconhecimento dessas populações como trabalhadores que dispõem de um sindicato - o Sindicato dos Trabalhadores Rurais (STR) - e de instituições profissionais capazes de defender seus interesses, como o Centro Nacional das Populações Tradicionais (CNPT). Com efeito, o que o contrato entre o Estado e as populações tradicionais evidencia no contexto da

${ }^{17}$ Com efeito, descendentes de seringueiros da época do ciclo da borracha, em sua maioria, essas populações são consideradas como detentoras de conhecimentos refinados da floresta e da sua biodiversidade florestal e marinha - os "saberes nativos", que Chico Mendes e o movimento do Acre buscaram reabilitar, denunciando o sistema de dominação que continuava a oprimi-las desde o fim do ciclo da borracha (Teisserenc, 2009) -, encontrando sua pertinência e legitimidade num contexto de ambientalização das questões internacionais, nacionais e locais.

${ }^{18}$ Mesmo se esses fatores não forem os mais determinantes, já que, como afirma Deborah de Magalhães Lima, tratase de uma "uma minoria não reconhecida, essencialmente porque ela não possui uma identidade étnica distinta da população dominante [...] que, por isso, necessita de um reconhecimento político."
Resex não é sua identidade como tal, mas os efeitos dessa identidade em termos de territorialidade (Little, 2002).$^{19}$ Essa territorialidade é herdada de seu passado seringueiro, que está na origem de sua capacidade para trabalhar de maneira autônoma e para gerir seu território num contexto de ambientalização que confere grande legitimidade a esse reconhecimento.

Disso resulta uma mobilização social das populações que, quando as condições sociais são propícias, encontram no Conselho Deliberativo o espaço público em que concentrarão o essencial de suas reivindicações e se beneficiam de um tratamento coletivo a partir do trabalho ali desenvolvido pelos representantes das populações e pelos seus diferentes parceiros sociais, técnicos e políticos envolvidos na implantação da Reserva e atingidos por seus efeitos sobre o desenvolvimento sustentável do território. Em seguida, veremos de que maneira a politização das questões locais resultante dos debates no seio do Conselho confere às decisões tomadas e às ações iniciadas por ele um caráter político, sempre que os parceiros locais reconhecem a qualidade deliberativa do trabalho do Conselho. ${ }^{20}$

Quando realizamos uma avaliação provisória do que essas duas situações têm em comum e do que as diferencia, concluímos que as diferenças de concepção da ação pública desempenham um papel importante, que explica, em particular, por que, no caso dos quilombolas, a prevalecente mobilização identitária redunda numa politização conflituosa das questões locais e por que, no caso das populações tradicionais, a criação da Resex está na origem (sempre que as circunstâncias forem favoráveis) de uma mobilização social capaz de contribuir para uma politização das questões locais, o que facilita o reconhecimento de

${ }^{19}$ Uma territorialidade é definida como "o esforço coletivo de um grupo social para ocupar, usar, controlar e se identificar com uma parcela específica de seu ambiente biofísico, convertendo-a efetivamente em seu território.” (Little, 2002, p. 3-4, apud Santilli, 2005, p. 138).

${ }^{20}$ Nos dois contextos, de Curuçá e de São João da Ponta, esse reconhecimento traduziu-se no resultado das eleições de 2008. 
toda sorte de engajamento como engajamento político. Essas constatações, resultantes das pesquisas conduzidas sobre as duas situações, e a análise que conduzimos nos permitiram identificar duas vias de integração da mobilização social no campo político, que serão apresentadas a seguir. ${ }^{21}$

\section{DUAS VIAS DE INTEGRAÇÃO DE UMA MOBILIZAÇÃO SOCIAL NO CAMPO POLÍTICO}

\section{A busca da integração de uma mobilização identitária no campo político}

A primeira via, que corresponde ao dispositivo implantado para responder à situação das comunidades quilombolas, caracteriza-se pelo cenário clássico, segundo o qual um grupo organizado e mobilizado em torno de questões identitárias e beneficiário de uma renovada legitimidade pela intervenção das autoridades públicas (preocupadas em dar uma resposta à situação dessas comunidades) reivindica, junto às autoridades locais, a aplicação concreta de seus novos direitos. Essa situação é exemplar de engajamentos políticos que se apoiam numa mobilização identitária que soube tirar partido పิ da introdução, na agenda política, da resposta . dada à situação de injustiça dos descendentes de quilombolas pela Constituição de 1988. Nós já evocamos a esse respeito a situação paradoxal que, para cada quilombola, cria a exigência de uma autoafirmação como a primeira etapa de um processo cujo objetivo é trazer para cada $\therefore$ um deles uma resposta coletiva, no contexto \& de um tratamento comunitário. Nós também já ơ evocamos o outro paradoxo, representado pelo $\therefore$ fato de que, na ausência de autoridades locais passíveis de suportar os seus efeitos em termos

${ }^{21}$ Não se trata de opor essas duas vias uma à outra, como se fossem incompatíveis, mas de descrever suas aplicações, levando em conta a filosofia política que inspira cada um desses dois dispositivos e apreciar seus efeitos, em cada um dos contextos, tendo em vista que é uma ou outra dessas duas vias que termina por se impor sobre cada um dos territórios, em função de circunstâncias e oportunidades. de aplicações secretas, essa situação de injustiça é tratada pelo nível federal.

Tendo em vista um contexto marcado pela permanência de um sistema de dominação, como foi dito anteriormente, e pela ausência de implicação das autoridades locais no tratamento da situação dos quilombolas, essa reivindicações tiveram dificuldade de ser ouvidas por essas autoridades. Disso resulta uma situação conflituosa, que opõe as comunidades quilombolas, como nova entidade social “auto-organizada”, ao poder local, que, por isso mesmo, tornou-se alvo de suas reivindicações. No artigo sobre a mobilização social dos quilombolas (Teisserenc, 2016), descrevemos a maneira como essa situação conflituosa se impôs por ocasião das eleições de 2004, 2008 e 2012. Nossa análise mostra como o caráter identitário dessa mobilização ${ }^{22}$ (Castro, 1997, p. 237) se traduz pelas reivindicações, no campo político, de um tratamento diferenciado da situação dos quilombolas, como se, na ausência de um sistema de direitos e vantagens diferenciadas, como é o caso das comunidades indígenas, esses direitos e vantagens se impusessem no campo político local, fazendo campanha principalmente pelo reconhecimento de suas particularidades sociais e culturais. É assim que se deve compreender sua vontade de integrar aos programas escolares a história da colonização e, nessa história, a situação particular dos quilombolas; o mesmo vale para suas demandas de aprendizado das práticas culturais negras no contexto escolar ${ }^{23}$ ou de organização de jogos olímpicos quilombolas. Deve-se considerar, no mesmo espírito, a importância, no campo da estratégia política, da

${ }^{22}$ O caráter identitário dessa mobilização se manifesta por meio de uma recrudescência e de uma valorização das festas, ritos e práticas, cuja função é caracterizar culturalmente as populações quilombolas e diferenciar seu território, que se impõe como o fundamento dessa identidade, como mostrou tão precisamente Edna Castro: "O reconhecimento dos lugares ocupados na história do grupo permite refazer dimensões específicas de ser e existir enquanto camponês e negro. O território é fundamental para a reprodução de sua existência e manutenção de sua identidade."

${ }^{23}$ Eles obtiveram ganho de causa por essas reivindicações. 
"carta de compromisso" ${ }^{24}$ que os candidatos à eleição de 2012 foram convidados a assinar e que comportava, especificamente, o pedido de uma representação permanente junto ao Prefeito de um conselheiro dotado de competência para tratar com ele de todas as questões relativas à situação dos quilombolas. ${ }^{25}$

A análise dessa carta de compromisso mostra até que ponto a mobilização dos quilombolas se aproxima da mobilização dos Novos Movimentos Sociais (NMS), que, geralmente, se apoiam em fatores identitários e cujas reivindicações colocam a ênfase na autonomia do movimento (Melucci, 1982; Touraine, 1984). Esses NMS "comportam uma forte dimensão expressiva, de afirmação de estilos de vida ou de identidades", com vistas a "construir contra os poderes públicos espaços de autonomia e reafirmar a independência de formas de sociabilidade privada contra a sua empresa" (Neveu, 2015, p. 61). Da mesma forma que o movimento quilombola, os NMS são levados a considerar, para superar a reivindicação de um "tratamento diferenciado reservado aos contestadores" que buscam interferir diretamente nos sistemas políticos e institucionais, "a estrutura de oportunidade política”, que resulta do "grau de abertura e de fechamento do sistema de poder local" (Neveu, 2015, p. 83-85). Esse não é, nem de longe, o caso de Salvaterra, onde os quilombolas buscam fazer valer, no campo político, as razões de sua mobilização social, desenvolvendo estratégias clássicas de influência e (ou) de conquista do poder a partir de jogos de alianças entre os líderes quilombolas e os candidatos à Prefeitura ou à Câmara. ${ }^{26}$

${ }^{24}$ Essa carta de compromisso se apresenta sob a forma de uma lista de reivindicações, que levam em conta todos os aspectos da vida das comunidades.

${ }^{25}$ Por ocasião dessas eleições, os quilombolas obtiveram ganho de causa, ao permitir a eleição de um Prefeito que tinha assinado essa carta de compromisso e que aceitou nomear como seu conselheiro o líder local das populações quilombolas, um homem de consenso, que afirma claramente que sua estratégia consiste - na ausência de direitos diferenciados, que a Constituição não reconhece às populações quilombolas - em negociar caso a caso com o Prefeito vantagens diferenciadas para responder à sua situação.

${ }^{26}$ Foi esse, em particular, o engajamento pessoal de Luzia Betânia Alcântara como líder a priori inconteste dos quilombolas.
Essas estratégias encontraram rapidamente seus limites. O primeiro limite se deve ao fato de que elas não se valem da mobilização social e da politização das questões locais que delas resultam para "se liberarem" ${ }^{27}$ (Boltanski; Chiapello, 1999, p. 521-522) de um poder local que repousa sobre um sistema de dominação, como foi dito anteriormente. É isso que explica o fato de os líderes quilombolas que se engajam no combate político serem levados a fazê-lo a título pessoal, com o objetivo de conquistar o poder pelo poder, sem manifestar uma vontade de mudar o sistema de dominação sobre o qual repousa o funcionamento da sociedade local. O segundo limite dessa estratégia resulta do uso feito pelos quilombolas do caráter identitário de sua mobilização e de sua tradução, sob a forma de reivindicações de vantagens diferenciadas. A identidade aqui referida é a identidade de uma entidade "auto-organizada”, que busca se impor nos debates públicos locais como um grupo estigmatizado, preocupado em denunciar as discriminações sofridas e obter compensação por meio das vantagens reivindicadas. Procedendo dessa maneira, eles privilegiam uma representação do território como a soma de espaços diferenciados sobre a base de critérios sociais, econômicos ou identitários, em detrimento de uma representação do território como "bem comum". Essa visão é muito pouco política, contribuindo para explicar os limites das estratégias às quais ela dá lugar. Como prova desses limites, citamos o fato de que as referidas estratégias foram questionadas, por ocasião das últimas eleições, pela candidatura a vereador de uma antiga presidente de associação comunitária que, dotada de forte personalidade e de grande legitimidade, fez campanha em defesa da agri-

27 Uma liberação no sentido dado ao termo por Luc Boltanski e Chiapello, "como liberação em relação a uma situação de opressão sofrida por um povo [...] que enfatiza as formas de dependência historicamente situadas, por meio das quais um coletivo sofre o jugo de um grupo que o domina. Tomada nesse sentido, a liberação é um ato político de reapropriação de uma autodeterminação e, indissociavelmente, uma maneira de escapar a uma opressão cultural e religiosa, bem como, em certos casos, de subtrair-se a uma forma ou outra de exploração.” 
cultura familiar (uma categoria socioprofissional da qual os quilombolas fazem parte e que representa metade dos ativos do município). Sua candidatura foi massivamente rejeitada pelos quilombolas, o que não a impediu de ser a primeira quilombola eleita vereadora depois de ter vencido o candidato "oficial".

\section{A busca de uma integração política a partir da coprodução de ação local ambiental no contexto de deliberação}

Bem diferente é a situação das populações tradicionais envolvidas na criação de uma reserva extrativista, na qual assistimos a uma mobilização que se inspira em dinâmicas de desenvolvimento territorial (Teisserenc, 2013) a partir de um projeto de território - cujo Plano de gestão da Resex é a tradução concreta - que, sendo capaz de responder às exigências ambientais, foi elaborado e implantado sob a responsabilidade do Conselho Deliberativo, com a participação das populações implicadas e do conjunto de seus parceiros sociais, técnicos e políticos. Esse projeto é o resultado de acordos negociados entre eles a partir de um bom uso dos instrumentos e dos recursos disponibilizados pela Resex como instrumento de política ○्: pública, num espírito de deliberação.

A análise dessa nova situação permite identificar uma segunda via de integração das questões da mobilização no campo político, que se caracteriza, quando da criação da reserva, por um novo conflito local, que opõe o poder local e a Resex, como instituição pública que dispõe de $\therefore$ uma legitimidade, de recursos e de instrumentos $\therefore$ oriundos do poder federal. Em seguida, quando iิ as circunstâncias o permitem - nos dois territó-

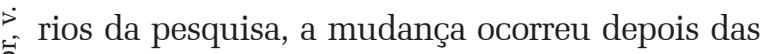
eleições de 2008, que trouxeram uma solução concreta ao conflito iniciado pelo reconhecimento da Resex como entidade permanente do território -, o trabalho conjunto empreendido pelos representantes das comunidades, pelos seus parceiros e pelo poder local no contexto do Conse- lho Deliberativo contribuiu para a politização das questões territoriais, resultantes da consideração dos desafios ambientais.

As pesquisas conduzidas sobre os dois territórios de Curuçá e de São João da Ponta mostraram que dois fatores característicos das Resex, como instrumentos de política pública, desempenhavam um papel importante para explicar as diferenças de situação entre a integração da mobilização das populações tradicionais e a mobilização dos quilombolas no campo político. O primeiro desses fatores é a questão ambiental, que confere legitimidade à Reserva e permite às populações mobilizadas nesse contexto encontrarem - no novo "repertório da ação coletiva local” com base nas questões ambientais (Tilly, 1986) - uma justificativa para o seu engajamento. ${ }^{28} \mathrm{O}$ segundo é a questão da deliberação, que deveria integrar o trabalho do Conselho Deliberativo. Essa questão confere a esse trabalho - em particular, às ações e às decisões que ele dá lugar, sempre que as circunstâncias são favoráveis para isso - um caráter político.

As situações vividas pelos municípios de Curuçá e de São João da Ponta, depois da eleição de 2008, confirmam a importância desses dois fatores para se compreender a politização das questões locais a partir do trabalho do Conselho Deliberativo e explicar o engajamento de um novo tipo de atores envolvidos na ação local. Com efeito, nossas observações indicam que essa politização das questões locais não se impõe como o resultado de uma mobilização de atores locais, preocupados em defender a aplicação de seus novos direitos, como é o caso dos quilombolas, mas muito mais como o efeito da participação dessas populações num trabalho de coprodução de ações e de projetos que se vale de um bom uso dos recursos e instrumentos disponibilizados pelo poder federal e da legitimidade gozada por essas populações e suas reivindicações no contexto da reserva. Esses dois fatores foram eficazes a partir do momento

${ }^{28}$ Lembremos que a consideração das exigências ambientais na elaboração de ações territoriais confere legitimidade à Resex e justifica o contrato que liga as populações tradicionais às autoridades políticas. 
em que o Conselho deliberativo se tornou efetivamente o lugar privilegiado de debates entre populações locais, especialistas e políticos, permitindo confrontações entre os saberes próprios a cada uma dessas categorias de atores (saberes acadêmicos, num caso, e saberes nativos, no outro), com vistas a dar um conteúdo concreto a uma gestão da biodiversidade do território, capaz de satisfazer às exigências ambientais. Essas confrontações permitiram aos atores implicados negociarem acordos, com vistas a dar respostas aos problemas locais. A experiência de "fóruns híbridos" ${ }^{29}$ (Callon, Lascoumes e Barthe, 2001) mostra que esses acordos, sempre que as circunstâncias o permitem, concretizamse pelo engajamento dos atores na ação local e se acompanham da produção de saberes sociotécnicos caracterizados por uma mistura de saberes acadêmicos e de saberes nativos.

Graças ao fato de que, no contexto da Resex, esses debates se desenvolvem no interior de uma nova instância - o Conselho Deliberativo, que se beneficia de um estatuto político reconhecido pela Constituição de $1988^{30}$ - e, a partir do momento em que as condições locais se mostram favoráveis a seu reconhecimento (particularmente, por causa da participação pessoal do Prefeito nos trabalhos do Conselho), o trabalho desse Conselho chega a decisões e projetos concernentes ao futuro do território e ao bem-estar de suas populações. Num tal contexto, esse processo se impõe como um trabalho político, como se a presença pessoal do Prefeito, que toma parte nos debates e nos seus resultados, constituísse uma espécie de garantia de reconhecimento do caráter político desse trabalho, no sentido em que o entende

${ }^{29}$ Esses "fóruns híbridos" são espaços de confrontações entre atores diferentes em torno de questões locais e espaços no interior dos quais pontos de vista contraditórios são trocados e acordos são negociados, o que engaja esses atores em respostas por eles dadas aos problemas identificados.

${ }^{30}$ Com efeito, a Constituição Brasileira de 1988 concede à deliberação um estatuto equivalente ao da representação; não é esse o caso, por exemplo, da Constituição Francesa atual que, por isso, cria um problema de conformidade constitucional cada vez que práticas participativas são iniciadas localmente.
Jacques Lagroye ${ }^{31}$ (Lagroye, 2003, p. 12).

O trabalho realizado no interior dos Conselhos deliberativos de duas Resex e os pontos de vista dos principais atores locais participantes desse trabalho reforçam nossa interpretação, no que diz respeito a: observações relativas ao funcionamento do Conselho, à sua organização, à introdução de seu programa de trabalho na agenda, etc.; observações relativas às missões do Conselho, à consideração beneficiada pelas populações locais, à sua imagem e à atratividade exercida sobre essas populações; questões relativas ao estatuto dos conselheiros, de sua representatividade e de sua maneira de assumir seu trabalho de representação; observações igualmente interessantes a respeito da qualidade das trocas, da qualidade dos atores e de seu aprendizado; e, finalmente, considerações no mínimo surpreendentes relativas a seu papel político, ligado ao caráter político das decisões tomadas e dos engajamentos coletivos, que não se limitam ao território da Reserva e tendem a levar em conta o conjunto do território municipal.

Todas essas observações permitem esclarecer a maneira pela qual a politização das questões locais se dá no interior do Conselho Deliberativo, num contexto territorial favorável, que acolhe a mobilização local num contexto de ambientalização. Em particular, elas mostram que esse trabalho repousa sobre um processo geral, que nada possui de linear, tendo em vista as dificuldades encontradas por diversos atores locais para satisfazer às exigências desse trabalho. Nesse sentido, Maria de Gloria Gohn tem razão em evocar a complexidade da institucionalização da deliberação e de sua integração no campo político ${ }^{32}$ (Gohn, 2013, p. 66-67).

31 Lembremos que, para Jacques Lagroye, a politização baseia-se sobre a requalificação em atividades políticas do trabalho resultante das formas de troca e de comunicações, das relações sociais e dos engajamentos de atores sobre as questões territoriais. Trata-se de uma requalificação que depende, essencialmente, de um acordo entre os atores envolvidos.

${ }^{32}$ A complexidade desse processo resulta especificamente do fato de que ele se alimenta de sucessos e fracassos, de idas e vindas em termos não apenas de mobilização, mas também de vontade de mudança, como atesta o fato de que, nas eleições locais de 2012 , a equipe municipal de 
Essas dificuldades são precisamente aquelas encontradas na implantação de ações coletivas que, iniciadas no contexto do Conselho, sejam capazes de satisfazer às exigências ambientais e que apareçam como ações inovadoras resultantes das trocas e confrontações entre técnicos-especialistas, políticos e membros da sociedade civil. Tirando proveito da valorização dos saberes nativos das populações tradicionais e dos saberes sociotécnicos que resultam das confrontações entre saberes acadêmicos e saberes locais, num contexto de deliberação, essas ações se justificam por referência à ideia de um bem comum que os debates permitem identificar ${ }^{33}$ (Teisserenc, 2013), e que se trata de defender e proteger. A implantação dessas ações faz com que elas sejam indicadoras desse trabalho de politização, que permite explicar por que esses atores, engajados nas práticas participativas, conseguem se entender sobre a ideia de um bem comum, cuja defesa e valorização devem contribuir para o desenvolvimento sustentável do território a partir da mobilização de suas populações.

Tais ações se caracterizam pela participação de políticos no trabalho de coprodução de ações locais, pela legitimidade que confere às populações tradicionais o reconhecimento de suas competências para satisfazer às exigências \& ambientais e pelo desafio que o caráter deliberaN tivo dos debates e dos engajamentos do Conselho

Curuçá não foi capaz de se reeleger, diferentemente do que se passou em São João da Ponta: "Mas todo esse processo de mudança no cenário da participação não tem sido

i gerado espontaneamente nem de forma harmoniosa [...].

क Foram as experiências que forneceram patamares referen-

స ciais e alimentaram as novas práticas [...]. Entretanto, o

2 exercício da democracia, em nome da cidadania de todos,

^ é um processo, não uma engenharia de regras. Como tal,

- ele demanda tempo, é construído por etapas de aproxima-

cões sucessivas, em que um erro é (ou deveria ser) tão pe-

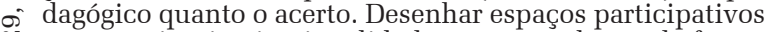

N e construir a institucionalidade correspondente, de forma

- a respeitar a diversidade, plural e aberta às identidades

ثิ de grupo/organização/movimento, exige articulações polí-

ticas que superem as divisões e costurem alianças, objetivando atingir determinadas metas."

${ }^{33}$ Essa noção de "bem comum" faz ela mesma referência à ideia de um "interesse geral de caráter local", oriundo

de um acordo entre atores no contexto de politização das

questões do território, um interesse geral cuja consideração serve de referência aos atores locais para justificar seu engajamento nas novas práticas de produção e de novas $\exists$ formas de organização de sua vida cotidiana. representa do ponto de vista da sua legitimidade política. Esse contexto explica por que, diferentemente do que constatamos nas comunidades quilombolas de Salvaterra, essa integração da mobilização social no campo político não se apresenta como o resultado de uma mobilização estritamente identitária contra o poder local, com vistas a afirmar e a fazer reconhecer a identidade diferenciada de seus membros, mas como o resultado de uma capacidade de coprodução de ações locais, no espírito de um desenvolvimento territorial sustentável, que contribui para a mudança do sistema de poder local pela implantação de práticas inovadoras que abrem novos caminhos para a democracia local. Diferentemente dos quilombolas, as populações tradicionais das duas Resex testemunham a capacidade de utilizar sua identidade legitimada em razão dos saberes nativos que ela inspira, num contexto de ambientalização, como um recurso que eles mobilizam numa perspectiva de desenvolvimento territorial sustentável ${ }^{34}$ (Bernstein, 1997).

\section{CONSIDERAÇÕES FINAIS}

A análise das duas situações que serviram de referência para este artigo - a das comunidades quilombolas de Salvaterra e a das comunidades tradicionais de Curuçá e de São João da Ponta, engajadas no contexto de uma Resex, - permitiu-nos identificar e descrever duas vias que permitem responder à questão inicial, motivada pelo questionamento de Alain Touraine sobre as condições de integração da mobilização social no campo político, privilegiando uma interpretação dessas duas situações em termos de ação pública.

A primeira situação é caracterizada por

${ }^{34}$ A partir dos trabalhos sobre as mobilizações homossexuais de caráter identitário nos EUA, Mary Bernstein mostra que a identidade mobilizada por esses grupos não se apresenta apenas como o resultado de um trabalho de afirmação no espaço público, mas também pode estar na origem de uma estratégia de ação coletiva Uma das consequências tiradas por Erik Neveu dessa análise é que, num plano teórico, ela nos convida a pensar que a identidade se apresenta menos como uma substância do que como um processo - o resultado de uma produção social (Neveu, 2015, p. 83). 
uma mobilização de natureza identitária em resposta às exigências do dispositivo proposto pela Constituição de 1988, com vistas a reparar a situação de injustiça das comunidades quilombolas, um século depois da abolição da escravidão e da Proclamação da República. O caráter identitário da mobilização justifica uma estratégia de defesa que se explica pelo duplo paradoxo presente na implantação do dispositivo. O primeiro resulta de um engajamento pessoal por meio de uma afirmação identitária, que dá origem a uma resposta comunitária por parte dos poderes públicos, e o segundo resulta de um tratamento oriundo da única competência das instâncias federais, enquanto as autoridades locais são diretamente envolvidas pela aplicação das medidas - e que se traduz por uma reivindicação de vantagens diferenciadas em direção do poder local. Essa mobilização se alimenta de uma afirmação identitária defensiva, no sentido sugerido por Alain Touraine (Touraine, 1984), que resulta de sua incapacidade para transformar a referência identitária em recursos a serviço da ação coletiva de caráter territorial. Além disso, em matéria de integração da mobilização social no campo político, as estratégias implantadas pelos quilombolas - que se apresentam como estratégias clássicas de influência e (ou) de tomadas de poder com vistas a reivindicar um tratamento político diferenciado - voltamse contra os limites impostos pela permanência de um sistema de dominação que aquelas estratégias não têm o objetivo de denunciar.

A segunda situação é caracterizada por uma mobilização de natureza social, mais do que identitária, já que essa mobilização prefere se apoiar sobre uma valorização dos conhecimentos tradicionais como recursos a serviço de uma dinâmica territorial de projeto. ${ }^{35}$ Essa mobilização se aproveita do enriquecimento das ações locais resultante da consideração das questões ambientais (Tilly, 1986), o que confe-

${ }^{35}$ E não de reivindicação de princípio, com vistas a satisfazer as exigências da reparação de uma injustiça, como é o caso dos quilombolas. re uma nova legitimidade de que as populações se beneficiam no contexto da Resex. Quando as circunstâncias o permitiram, como foi o caso dos dois princípios de Curuçá e de São João da Ponta depois das eleições de 2008, essa mobilização social encontrou a via de sua integração no campo político a partir do trabalho do Conselho Deliberativo, que soube tirar partido de sua legitimidade constitucional para coproduzir ações coletivas locais que conseguiram se impor localmente como ações políticas. Essa mobilização pela ação coletiva se apoia sobre as estratégias dos atores locais e de seus parceiros, que são conscientes do caráter inovador de suas práticas e de seu engajamento. Essas práticas compreendem os modos de produção desenvolvidos por essas populações, os modos de vida e as formas de democracia implementadas no território. Elas se apresentam como o resultado de experimentações ${ }^{36}$ que tocam todos os domínios da vida local e, em particular, o trabalho deliberativo no interior do Conselho. Compreende-se, assim, por que essas mudanças questionam o modelo de desenvolvimento do território (Maglhães Lima, 2002, p. 17) e abrem novas possibilidades de "governança territorial sustentável” (Dallabrida, 2003; Teisserenc, 2014; Theys, 2002). Essas perspectivas não significam o fim dos conflitos nem a substituição de um modelo de desenvolvimento por outro. Pelo contrário, elas testemunham a emergência de uma sociedade local que privilegia apreender a complexidade dos problemas identificados, tirando proveito das formas de mobilização de todos os recursos e o uso inteligente dos instrumentos colocados à disposição para trazer respostas aos conflitos, antigos e novos, e para satisfazer às exigências para um futuro escolhido.

\section{Tradução do francês por Daniel Padilha Pacheco da Costa}

Recebido para publicação em 10 de janeiro de 2016 Aceito em 23 de abril de 2016

\footnotetext{
36 "As reservas extrativistas constituem um experimento social com todas suas dificuldades de realização e seus riscos de desvios.” (Aubertin; Pinton, 1997, p. 282).
} 


\section{REFERÊNCIAS}

ALMEIDA, Mauro William Barbosa. Direitos à floresta e ambientalismo: os seringueiros e suas lutas. Revista Brasileira de Ciências Sociais, São Paulo, v. 19, n. 55, p 33-53, 2004.

AUBERTIN, Catherine; PINTON, Florence. O extrativismo entre a conservação e o desenvolvimento. In: CASTRO, Edna; PITON, Florence. Faces do trópico úmido. Conceitos e questões sobre desenvolvimento e meio ambiente. Belém: Editora Cejup, 1997.

AUBERTIN, Catherine; PINTON, Florence. De nouvelles frontières du développement durable: la construction des espaces de droits en Amazonie brésilienne. In: ALBALADEJO, Christophe; TULET, Jean-Christian (Org.). Fronts pionniers de l'Amazonie brésilienne. Paris: l'Harmattan, 1996.

BERNO DE ALMEIDA, Alfredo Wagner et al. (Orgs.). Territórios quilombolas e conflitos.Manaus: Nova Cartografia Social da Amazônia-PNCSA, 2010.

BERNO DE ALMEIDA, Alfredo Wagner. Antropologia dos arquivos da Amazônia. Rio de Janeiro: Casa 8 / F.U.A, 2008.

BERNSTEIN, Mary. Celebration and suppression: the strategic uses of identity by the lesbian and gay movement. American Journal of Sociology, Chicago, v. 103, n. 3, p. 531-565, 1997.

BOLTANSKI, Christian; CHAPELLO, Eve. Le nouvel esprit du capitalisme. Paris: Gallimard, 1999.

CALLON, Michel; LASCOUMES, Pierre; LABARTHE, Yves. Agir dans un monde incertain. Essai sur la démocratie technique. Paris : Le Seuil, 2001. (La couleur des idées) .

CEFAI, Daniel. et al. (Org.). Arenas públicas: por uma etnografia da vida associativa. Niterói: Editora da UFF, 2011.

CASTRO, Edna. Território, biodiversidade e saberes de populações tradicionais. In: CASTRO, Edna; PITON, Florence. Faces do trópico úmido. Conceitos e questões sobre desenvolvimento e meio Ambiente. Belém: Editora Cejup, 1997.

DALLABRIDA, Valdir Roque. Governança territorial. Um primeiro passo na construção de uma proposta teóricometodológica. Desenvolvimento em questão, Ijui, v.1, n. 2, o p. 73-98, 2003.

จ GOHN, Maria da Glória. Conselhos gestores e participação $\dot{8}$

GOMES, Flavio dos Santos. A Hidra e os pontenos: mamcombos, quilombolas e comunidades de figitivos no Brasil século XVII-XIX. São Paulo: Ed. UNESP Polis, 2005.

î GONÇALVES, Carlos Porto Walter. Amazônia, Amazônias. ஸ São Paulo: Editora Contexto, 2001.

भั

‡ LAGROYE, Jacques. (Org.). La politisation. Paris: Belin, i. (2003).

^ LEFF, Enrique. Racionalidade ambiental. A reapropriação \& social da natureza. Rio de Janeiro: Civilização Brasileira, 2006.

กิ

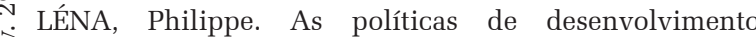

sustentável para a Amazônia: problemas e contradições.

50 Boletim Rede Amazônia, Rio de Janeiro, Ano 1, n. 1, p. 9-20, 2002.

กี LOPES, Jose Sérgio Leite. Sobre processo de "ambientalização" dos conflitos e sobre dilemas da participação. Horizontes Antropológicos, Porto Alegre, ano 12, n. 25, p. 31-64, 2006.

MAGALHÃES LIMA, Deborah. Éthique et politique environnementale en Amazonie contemporaine. Lusotopie: [s.n], 2002. p. 13-23.
MELUCCI, Alberto. L'Invenzione de presente. Movimenti, identita, bisogni individuali. Bologne: Il Mulino, 1982.

MOTA, Fabio Reis. Quanto custa ser quilombolas no Brasil? Mobilizações coletivas e associativismo no Brasil contemporâneo. In: CEFAI, Daniel et al. (Org.). Arenas públicas. Por uma etnografia da vida associativa. Niteroi: Editora da UFF, 2011. p. 239-262.

NEVEU, Erik. Sociologie des mouvements sociaux. Paris: La Découverte, 2015.

O'DWYER, Eliane Cantarino. Remanescentes de quilombos na fronteira amazônica: a etnicidade como instrumento de luta pela terra. Boletim Rede Amazônia, Rio de Janeiro, Ano 1, n. 1, p. 77-86, 2002.

SANT'ANA JUNIOR, Horácio Antunes de; PIRES MIRANDA, Ana Carolina. Conflitos ambientais na Amazônia e a construção de catagorias sociológicas e jurídicas: análise da expressão povos e comunidades tradicionais. Revista Pós Ciências Sociais, São Luiz v. 10, n. 20, p. 103-120, jul./dez. 2013.

SANTILLI Juliana. Biodiversidade e conhecimentos tradicionais associados: novos avancos e impasses na criação de regimes legais de proteção. In: LIMA, André; BENSUSAN, Nurit (Org.). Quem cala consente?: subsídios para a proteção aos conhecimentos tradicionais. São Paulo: ISA, 2003.

SANTILLI, Juliana. Socioambientalismo e novos direitos: proteção jurídica à diversidade biológica e cultural. São Paulo: Peirópolis, 2005.

SAQUET, Marcos. Abordagens e concepções de território. São Paulo: Expressão Popular, 2007.

TEISSERENC, Pierre. A governança territorial a partir da experiências das reservas extrativistas. Revista PósCiências Sociais, São Luiz, v. 11, n. 22, p.19-41, 2014.

TEISSERENC, Pierre. L'interprétation sociologique de l'intérêt public local. In: CHICOT, Pierre-Yves; ETIEN, Robert; TEISSERENC, Pierre. (Org.). L'influence des régimes juridiques des collectivités d'outre-mer sur l'évolution de l'Etat français. Paris: Editions Cujas, 2013. (Actes et Études).

TEISSERENC, Maria José da S. A. Politização, ambientalização e desenvolvimento territorial em Reservas Extrativistas. Caderno CRH, Salvador, v. 29, n. 77, p.229-242, Maio/Ago. 2016

TEISSERENC, Pierre. L'action publique dans ses nouveaux territoires en France et au Brésil. Paris: L’Harmattan, 2013. (Administration et Aménagement du territoire).

TEISSERENC, Pierre. Poder local e condições de sua renovação na Amazônia. Novos Cadernos NAEA, v. 19, n. 1, p.47-70, jan-abril, 2016.

TEISSERENC, Pierre. Les Resexs: un instrument au service des politiques de développement durable en Amazonie brésilienne. Dossiê: Amazônia e paradigmas de desenvolvimento. Revista Pós Ciências Sociais, São Luiz, v. 6, n. 12, p. 41-68, 2009.

THEYS, Jacques. La gouvernance entre innovation et impuissance :le cas de l'environnement. In:Développement durable et territoires, dossier 2: gouvernance locale et développement durable. [S.l.;s.n], 2002.

TILLY, Charles. La France conteste de 1660 à nos jours. Paris: Harvard University Presse,1986.

TOURAINE, Alain. La fin des sociétés. Paris: Ed. du Seuil, 2013. (Colletion Essais). . Le retour de l'acteur. Paris: Fayard,1984. 


\section{INTEGRATION PATHWAYS FOR SOCIAL MOBILIZATION IN THE POLITICAL ARENA}

\author{
Pierre Teisserenc
}

This article analyzes two situations of integration in the political arena. The situations were identified through qualitative research in Quilombola Territories and in Marine Extractive Reserves in the State of Pará. One situation corresponds to the constitutional judicial instrument for reparation of historical injustices, mobilizing of specific identities in mobilization to interfere in the local government of the Municipality of Salvaterra (Marajó Archipelago). The identity character of the claims and the inexistence of public spaces to negotiate them reduce the likelihood of achieving social rights. The other, known as Resex (extractive reserve) - instrument of public policy related more to social than to an identity mobilization instrument - referred in the recognition of traditional populations and their adequate knowhow in relation to environmental demands. Tools such as the Deliberative Council, under certain circumstances provide favorable spaces for innovation in livelihood, economic production, involvement of local players in collective action, consequently renewing local democracy within an environmental context.

Keywords: Political arena. Social Mobilization. Mots-cLÉs: Champ politique. Mobilisation sociale. Identity.LocalPoliticalPower.Environmentalization. Identité. Pouvoir local. Ambientalizacão.

\section{LES VOIES D'INTEGRATION DE LA MOBILISATION SOCIAL DANS LE CHAMP POLITIQUE}

Pierre Teisserenc

Cet article analyse deux situations d'intégration de la mobilisation sociale dans le champ politique. Ces situations ont fait l'objet d'une analyse qualitative, l'une en territoires Quilombolas et l'autre en Réserves Extractivistes Marines dans le Para. La première est caractérisée par l'application d'un instrument juridique constitutionnel dans le but de réparer des injustices historiques dont l'effet mobilisateur interfère sur le pouvoir local à Salvaterra (Ile de Marajo). Le caractère identitaire des revendications et l'absence d'espaces publics pour les négocier réduisent les possibilités de faire valoir les droits sociaux des communautés. La seconde situation, la Resex - un instrument de politique publique à l'origine d'une mobilisation plus sociale qu'identitaire - privilégie la reconnaissance des populations traditionnelles et de leurs savoir-faire susceptibles de satisfaire les exigences environnementales. Les outils que la Resex mobilise, comme le Conseil Délibératif, contribuent, selon les circonstances, à favoriser des innovations tant en matière de modes de vie et de production économique qu'en matière d'engagement des acteurs locaux dans des actions collectives, contribuant ainsi à la rénovation de la démocratie locale dans un contexte d'ambientalização.

Pierre Teisserenc - Doutor em Sociologia pela Université Paris-Descartes, Sorbonne e École des Hautes Études en Sciences Sociales. Professor Emérito desde 2011 da Université Paris 13, onde fundou o Centre de Recherhes sur l'Action Locale. Em 2008 iniciou colaboração, enquanto professor visitante, com a Universidade Federal do Pará, tanto no Programa de Pós-Graduação em Sociologia e Antropologia quanto no Programa de Pós-Graduação em Gestão dos Recursos Naturais e Desenvolvimento Local na Amazônia. Atualmente é Bolsista Visitante Sênior (Fapespa) 2016-2018, na UFPA. Publicações recentes: Ação local e território de desenvolvimento sustentável. In: Sociologia e Antropologia, Revista do Programa de PósGraduação em Sociologia e Antropologia da Universidade Federal do Rio de Janeiro. Jan.Jun./2014; L’Action publique dans ses nouveaux territoires en France et au Brésil. Paris: L’Harmattan, 2013. 
